\title{
Outcomes of traumatic brain injury among pediatric population presenting in emergency room
}

\author{
Jayapal K. ${ }^{\text {, }}$ Mansour H.A. ${ }^{2}$ \\ ${ }^{1}$ Dr. Karthick Jayapal, Specialist ER Pediatrics, Dr. Hassan Adnan Mansour, Consultant ER Pediatrics; both authors are \\ attached with Dr. Sulaiman Al Habib Hospital, Riyadh, Saudi Arabia
}

Corresponding Author: Dr. Karthick Jayapal, Specialist ER Pediatrics. Dr. Sulaiman Al Habib Hospital, Riyadh, Saudi Arabia. E-mail: Karthickchildcare@gmail.com

\begin{abstract}
Background: Traumatic Brain Injury (TBI) is one of the most common cause of Emergency Room (ER) visits in the pediatric age group. Severe TBI can result in impairment of higher cognitive functions and can also limit physiological functions like motor, speech and emotional problems. This study was carried out to evaluate the outcomes of TBI among pediatric patients presenting in ER. Methods: This cross-sectional study was carried out among 175 pediatric patients visiting the emergency room with a diagnosis of traumatic brain injury. Patient with moderate to severe traumatic head injury within 72 hours and those aged $1-15$ years were included. Glasgow coma scale was used to assess and grade the severity of the TBI. Glasgow Outcome Scale was used to grade the outcomes following TBI. Results: As per the Glasgow Outcome Scale (GOS), majority of the participants were graded with mild disability and good recovery (64\%), while 6 patients were graded to be dead and $4.6 \%$ of the participants were graded to be in vegetative state. In this study, significant correlation between severity of the TBI and its outcome. Moderate TBI was associated with better outcomes compared to severe TBI. The association was found to be statistically significant $(p<0.0001)$. Conclusion: Considering the impact of specific causes of TBI namely motor vehicle accidents and fall from height, there is a need for implementation of rigorous legislations which can minimize the risk for such accidents involving the pediatric age groups. It is essential to create safe public places, which are not only utility based, but also enable vulnerable age groups access them with minimal risk.
\end{abstract}

Keywords: Emergency Room, Traumatic Brain Injury, Glasgow Coma Scale, Glasgow Outcome Scale

\section{Introduction}

Traumatic Brain Injury (TBI) is one of the most common cause of Emergency Room (ER) visits in the pediatric age group. These injuries are often trivial, predominantly consisting of falls. While most of these children sustain minor injuries, some of the patients develop serious consequences resulting in physiological and neurological derangements. Studies have shown that TBI is the major cause of death and disability among children aged 1-15 years [1].

According to CDC estimates, mild TBI is witnessed in $70-80 \%$ of the ER visits while moderate and severe TBI are seen in $15 \%$ and $2 \%$ of the ER visits respectively [2]. Among the developing countries, pediatric head trauma is seen in $20-30 \%$ of all the head injuries [3].

Manuscript received: $10^{\text {th }}$ September 2019

Reviewed: $20^{\text {th }}$ September 2019

Author Corrected: $25^{\text {th }}$ September 2019

Accepted for Publication: 30
In a pediatric setup, majority of TBI result from fall from height $(50 \%)$ or road traffic accidents (42\%) [4]. The complications that occur following TBI may be physiological, psychological or neurological. Based on Glasgow coma scale scoring (duration and intensity of loss of consciousness), traumatic brain injury can be categorized ad mild or severe. Severe TBI can result in impairment of higher cognitive functions and can also limit physiological functions like motor, speech and emotional problems. Moreover, the pattern of injury has great impact on the general wellbeing and functioning of the child.

The head injuries are unique in the pediatric age group, owing the distinctive characteristics in the anatomy and physiology of the brain, characterized by neuroplasticity. TBI has severe impact on not only the 


\section{Original Research Article}

physical and physiological wellbeing but also on the social well-being of the patients.

The effects present a major social, economic and health problems during long stay in hospital, permanent neurological disability, long term rehabilitation facilities, complications associated with long hospital stay, straining the available resources and loss of earning power and death involving not only the patients but also the care providers. Several factors like physiological changes, etiology, management and its outcome are related with the traumatic brain injury in children. Every parameter has to be evaluated in depth, for the better prediction of outcome in traumatic brain injury in the Emergency Room. A thorough analysis of these factors will help in long run to devise preventive strategies and programs for early detection, which can minimize the impact of the traumatic brain injury on the child, decrease in hospital stay duration and complications associated with TBI.

\section{Objectives}

This study was carried out to evaluate the outcomes following traumatic brain injury among pediatric population visiting the Emergency Room

\section{Methodology}

Study setting and participants: This cross-sectional study was carried out among the pediatric patients visiting the emergency room with a diagnosis of traumatic brain injury for a period of 32 months from January 2016 to August 2018 .

\section{Inclusion criteria}

- Patient with moderate to severe traumatic head injury within 72 hours

- Patients age 1 - 15 years old.

\section{Exclusion criteria}

- Mild head injury

- Patient admitted due to causes other than trauma

- Patients with previous neurological problems.

- Patients who presented beyond 72 hours

- Patients $<1$ and $>15$ years of age.

Ethical approval and informed consent: Approval was obtained from the Institutional Ethics Committee prior to the commencement of the study.

Each participant's parents/ guardian was explained in detail about the study and informed consent was obtained prior to the commencement of data collection.

Sample size calculation and sampling: Based on the available literature, it was observed that the overall prevalence of TBI among children and young adults was 30\% [2]. At 95\% confidence limits and 7.5\% absolute precision, the sample size was calculated as 143 . Accounting $10 \%$ for refusals, the sample size was calculated as 158 and was rounded off to 175.

All patients admitted to the Emergency department of our hospital who fulfill selection criteria were selected for the study. The participants were selected by purposive sampling technique.

Data collection: On presentation at the ER, clinical examination was carried out to evaluate the external wounds and other associated injuries. Glasgow coma scale was used to assess and grade the severity of the TBI [5]. Glasgow Outcome Scale was used to measure the outcome of TBI [6].

A grade of 1,2,3 were classified as poor outcome and 4,5 as good outcome.

Data analysis: Data was entered and analyzed using SPSS ver. 21 software. The prevalence of TBI was expressed in percentages. The correlation between Glasgow outcome scale and Glasgow Coma Scale was analyzed using chi square test. A p value $<0.05$ was considered statistically significant.

Pediatric Review: International Journal of Pediatric Research Available online at: www.medresearch.in 496|P a g e 


\section{Original Research Article}

Table-1: Glasgow outcome scale interpretation.

\begin{tabular}{|c|c|c|c|}
\hline S. No & Disability & Characteristics & Scale \\
\hline 1 & Mild & Good recovery with or without mild disability & 5 \\
\hline \multirow[t]{3}{*}{2} & \multirow[t]{3}{*}{ Moderate } & Loss of consciousness beyond 30 minutes & \multirow[t]{3}{*}{4} \\
\hline & & Physical or cognitive impairment which may or may not resolve & \\
\hline & & Benefit from rehabilitation & \\
\hline \multirow[t]{7}{*}{3} & \multicolumn{3}{|l|}{ Severe } \\
\hline & Coma & $\begin{array}{l}\text { Unconscious state. No meaningful response; no voluntary } \\
\text { activities }\end{array}$ & 3 \\
\hline & \multirow[t]{3}{*}{ Vegetative state } & Sleep wake cycles & \multirow[t]{4}{*}{2} \\
\hline & & Arousal, but no interaction with the environment & \\
\hline & & No localized response to pain & \\
\hline & Persistent vegetative state & Vegetative state lasting longer than one month & \\
\hline & Brain death & No brain function & 1 \\
\hline
\end{tabular}

\section{Results}

This study was carried out among 175 participants who were admitted to the Emergency Room following TBI. Majority of the participants were $<5$ years of age $(70.8 \%)$ and were males $(60 \%)$. Most of the participants were brought to the ER within 1-2 hours of injury (28\%). About $6.9 \%$ of the participants were brought beyond 4 hours of the trauma. (Table 2).

Table-2: Background characteristics.

\begin{tabular}{|c|l|c|c|}
\hline S. No & \multicolumn{1}{|c|}{ Characteristics } & Frequency (N=175) & Percentage (\%) \\
\hline $\mathbf{1}$ & Age & 124 & 70.8 \\
\hline & $1-5$ years & 51 & 29.2 \\
\hline & 6-10 years & 105 & 60.0 \\
\hline $\mathbf{2}$ & Gender & 70 & 40.0 \\
\hline & Male & \multicolumn{2}{|c|}{} \\
\hline & Female & 104 & 59.4 \\
\hline $\mathbf{3}$ & Mode of injury & 19 & 10.9 \\
\hline & Fall from height & 52 & 29.7 \\
\hline & Fall of object & \\
\hline
\end{tabular}

The grading and outcome of trauma among the study participants is given in table 3. As per the Glasgow Coma Scale grading, majority of the participants $(70.9 \%)$ belonged to moderate TBI and $29.1 \%$ belonged to severe TBI. As per the Glasgow Outcome Scale (GOS), majority of the participants were graded with mild disability and good recovery (64\%), while 6 patients were graded to be dead and $4.6 \%$ of the participants were graded to be in vegetative state (Table 3 ).

Table-3: Grading and outcome of trauma.

\begin{tabular}{|c|c|c|c|}
\hline S. No & Characteristics & Frequency $(\mathrm{N}=175)$ & Percentage (\%) \\
\hline \multirow[t]{4}{*}{1} & \multicolumn{3}{|l|}{ Glasgow coma scale } \\
\hline & Mild & 0 & 0.0 \\
\hline & Moderate & 124 & 70.9 \\
\hline & Severe & 51 & 29.1 \\
\hline \multirow[t]{6}{*}{2} & \multicolumn{3}{|l|}{ Glasgow Outcome Scale } \\
\hline & Death & 6 & 3.4 \\
\hline & Vegetative state & 8 & 4.6 \\
\hline & Severe disability & 12 & 6.9 \\
\hline & Moderate disability & 37 & 21.1 \\
\hline & Mild disability/Good recovery & 112 & 64.0 \\
\hline
\end{tabular}




\section{Original Research Article}

In this study, significant correlation between severity of the TBI and its outcome. Moderate TBI was associated with better outcomes compared to severe TBI. The association was found to be statistically significant $(p<0.0001)$. (Table 4$)$.

Table- 4: Comparison between grade of TBI and outcome.

\begin{tabular}{|c|c|c|c|c|c|c|c|c|}
\hline \multirow[t]{2}{*}{ S. No } & \multirow[t]{2}{*}{ Characteristics } & \multirow[t]{2}{*}{ (N) 175} & \multicolumn{2}{|c|}{ GOS } & \multirow{2}{*}{$\begin{array}{l}\text { Chi } \\
\text { sq }\end{array}$} & \multirow[b]{2}{*}{ OR } & \multirow[t]{2}{*}{$P$ value } & \multirow{2}{*}{$\begin{array}{c}\text { CI } \\
(95 \%)\end{array}$} \\
\hline & & & $\begin{array}{c}\text { Good } \\
\text { outcome }\end{array}$ & $\begin{array}{c}\text { Poor } \\
\text { outcome }\end{array}$ & & & & \\
\hline \multirow[t]{3}{*}{1} & \multicolumn{8}{|c|}{ GOS evalution after 72 hours } \\
\hline & Moderate TBI & 124 & $115(92.7)$ & $9(7.3)$ & \multirow[t]{2}{*}{19.4} & \multirow[t]{2}{*}{6.4} & \multirow[t]{2}{*}{$<0.0001^{*}$} & \multirow{2}{*}{$\begin{array}{l}1.2- \\
15.5\end{array}$} \\
\hline & Sereve TBI & 51 & $34(66.7)$ & $17(33.3)$ & & & & \\
\hline
\end{tabular}

*Statistically significant

\section{Discussion}

Traumatic Brain Injury (TBI) occurs due to external mechanical force to the cranium and intra cranial structures resulting in temporary or permanent impairment, functional disability and psychosocial maladjustment. The impact of TBI results in two sets of damages - the primary injury which occurs at the moment of trauma and secondary injury which occurs immediately following trauma and produces effects which may last for a longer duration [7].

Although traumatic brain injury is fairly less common among adults, it is one of the leading causes of ER visit among the pediatric population. In our study among 175 patients, males were predominant and TBI was higher in the age group of 1-5 years. In a study done by Chaitanya $\mathrm{K}$ et al, the mean age of the affected participants was 5.5 years, similar to our study [8]. In our study, majority of the participants suffered from moderate TBI $(70.8 \%)$ while $29.2 \%$ suffered from severe TBI. In this study, majority of the participants had favorable outcome, who had moderate TBI. Children who had moderate traumatic brain injury showed better outcomes than compared to other group with severe TBI $(\mathrm{p}<0.001)$.

It's challenging to analyze the morbidity following traumatic brain injury in children. Early reports by Kraus et al observed that $97 \%$ of the children were discharged alive and well following TBI [9]. Another study by Falk et al observed that $4.3 \%$ of the children develop neurological symptoms beyond a lucid interval [10]. In a study done by Forsyth et al, 6\% of the admissions with TBI were discharged with conservative management and rehabilitative measures [11]. However, very few studies have reported mild injuries following trauma. The brain of the child is constituted with $88 \%$ of water, thereby making them soft and vulnerable to external damage. Head trauma in the pediatric age group causes rotational acceleration-deceleration of the head generating shearing forces that cause mechanical disruption of nerve fibres. As a consequence, there is diffuse axonal injury resulting in large subdural hematomas [12]. In cases where the child experiences direct blow causing linear fracture across meningeal arteries, epidural hematoma ensues further complicating the outcomes. [13].

Traumatic brain injury is followed by Neuro protective mechanism which is a natural rebound mechanism of the brain tissue. Neuroprotective mechanisms for acquired and chronic trauma have been based on the response from astrocytes, microglia, oligodendrocytes, and precursor cells [14]. These mechanisms play an important role in the therapeutic strategies which promotes recovery and functioning of the non-neuronal cells. The neuronal cell death the Neuro productive mechanisms may be described under neuronal cell death whose morphology may be based on intrinsic apoptosis, extrinsic apoptosis, regulator necrosis and autophage [15].

Considering the severity of the impact of TBI, it is essential to devise adequate guidelines and regulations for preventing TBI among pediatric age group. This should involve multi-sectoral participation including schools, parent groups, and public infrastructure planners. Strong policy decisions should be taken and effectively implemented to curb violations which result in fatal and near fatal accidents involving TBI. As a rehabilitative measure, there is a need for effective training and health education strategies for health care professionals to provide holistic management of TBI. It is essential to provide rehabilitation at all levels, including cognitive, behavioral and psychomotor components. There should be inclusive participation from the parents and other care providers during the 


\section{Original Research Article}

rehabilitative period in order to facilitate easy coping mechanisms for the children, so as to restore quality of life and normal childhood among these patients.

The lack of success of neuroprotective drugs clinically has led investigators to identify potential factors contributing to such failures. These include (1) inadequate understanding of secondary injury mechanisms; (2) insufficient preclinical testing in multiple injury models, strains, species (including gyrencephalic), genders and ages; (3) lack of thorough investigation of pharmacokinetics and therapeutic brain concentrations; (4) failure adequately to examine therapeutic window and clinically relevant behavioral outcomes; (5) use of heterogeneous patient populations; (6) inadequate sample size; and (7) inadequate functional outcome measurements and biomarkers [16].

Limitations: This study has been conducted on a limited sample of patients in a hospital setting. In order to facilitate generalization, this study needs to be replicated in the community.

\section{Conclusion}

Traumatic Brain Injuries (TBI) are associated with increased morbidity and mortality, especially in the pediatric age group. In spite of aggressive clinical and surgical management, TBI often results in physical and or neurological deficit. There are several molecular mechanisms underlying the neuronal cell death and damage. Considering the magnitude of impact caused by TBI, it is essential to analyze the key factors associated with the prognosis of TBI. Considering the impact of specific causes of TBI namely motor vehicle accidents and fall from height, there is a need for implementation of rigorous legislations which can minimize the risk for such accidents involving the pediatric age groups. It is essential to create safe public places, which are not only utility based, but also enable vulnerable age groups access them with minimal risk.

\section{What the study adds to the existing knowledge?}

The present study has also been successful in engineering various hypotheses regarding the predictors of TBI at the molecular level which paves way for further research in the future

\section{Author's contribution}

Dr. Karthick Jayapal: Conceptualization and writing Dr. Hassan Ali Mansour: Data collection and analysis

\section{Declaration}

Funding: Nil, Conflict of interest: None initiated, Permission from IRB: Yes

Ethical approval-Obtained

\section{References}

1. Cheung PS, Lam JM, Yeung JH, Graham CA, Rainer TH. Outcome of traumatic extradural haematoma in Hong Kong. Injury. 2007 Jan 1;38(1):76-80. doi: https://doi.org/10.1016/j.injury.2006.08.059

2. The L. The burden of traumatic brain injury in children. The Lancet 2018;391(10123):813. doi: https://doi.org/10.1016/S0140-6736(18)30547-6.

3. Mahapatra AK, Kumar R. Pediatric Head injury. In: Mahapatra AK, Kumar R, Kamal R, editors. Textbook of Head Injury. Delhi: Jaypee Publ. 2012; 180-190.

4. Opondo E. Factors influencing outcome of severe head injury at Kenyatta National Hospital. MMED Thesis, University of Nairobi. 2005.

5. Jain S, Teasdale GM, Iverson LM. Glasgow Coma Scale. StatPearls.

6. Oliviera RA, Araujo S, Falcao ALE, Soares SMTP, Kosour C, Dragosavac D et al. Glasgow outcome scale at hospital discharge as a prognostic index in patients with severe traumatic injury. Arq Neuro Psiquiatr 2012;70(8):604-608. doi: http://dx.doi.org/10.1590/ S0004-282X2012000800009.

7. McKee AC, Daneshvar DH. The neuropathology of traumatic brain injury. Handb Clin Neurol 2015; 127:45-66. doi: 10.1016/B978-0-444-52892-6.00004-0.

8. Chaitanya K, Addanki A, Karambelkar R, Ranjan R. Traumatic brain injury in Indian Children. Childs Nerv Syst 2018;34(6):1119-1123. doi: 10.1007/s00381-0183784-z.

9. Kraus MF, Susmaras T, Caughlin BP, Walker CJ, Sweeney JA, Little DM. White matter integrity and cognition in chronic traumatic brain injury: a diffusion tensor imaging study. Brain 2007;30(Pt 10):2508-2519. doi: https://doi.org/10.1093/brain/awm216.

10. Papa L, Lewis LM, Falk JL, Zhang Z, Silvestri S, Giordano $\mathrm{P}$ et al. Elevated levels of serum glial fibrillary acidic protein breakdown products in mild and moderate traumatic brain injury are associated with intracranial lesions and neurosurgical intervention. Ann

Pediatric Review: International Journal of Pediatric Research Available online at: www.medresearch.in 499|P a g e 


\section{Original Research Article}

Emerg Med. 2012;59(6):471-483. doi: 10.1016/ j.annemergmed. 2011.08.021.

11. Forsyth R, Kirkham F. Predicting outcome after childhood brain injury. CMAJ 2012;184(11):12571264. doi: 10.1503/cmaj.111045.

12. Andras B, Povlishock, J.T. All roads lead to disconnection? - Traumatic axonal injury revisted. Acta Neurochirurgica. $\quad 2006 ; 148 \quad$ (2):181-193. doi: https://doi.org/10. 1007/s00701-005-0674-4.

13. Schutzman S. Minor head trauma in infants and children: Evaluation.[Internet] Available from https://www.uptodate.com/contents/minor-head-traumain-infants-and- children-evaluation.
14. Bylicky MA, Mueller GP, Day RM. Mechanisms of endogenous neuroprotective effects of astrocytes in brain injury. Oxid Med Cell Longev. 2018;2018: 6501031. doi: 10.1155/2018/6501031.

15. Becerra-Calixto A, Cardona-Gomez GP. The role of astrocytes in neuroprotection after brain stroke: potential in cell therapy. Front Mol Neurosci. 2017;10:88. doi: 10.3389/fnmol.2017.00088.

16. Loane DJ, Faden AI. Neuroprotection for traumatic brain injury: translational challenges and emerging therapeutic strategies. Trends Pharmacol Sci. 2010;31(2):596-604. doi: 10.1016/j.tips.2010.09.005.

\section{How to cite this article?}

Jayapal K., Mansour H.A. Outcomes of traumatic brain injury among pediatric population presenting in emergency room. Int J Pediatr Res.2019;6(09):495-500.doi:10.17511/ijpr.2019.109.10 